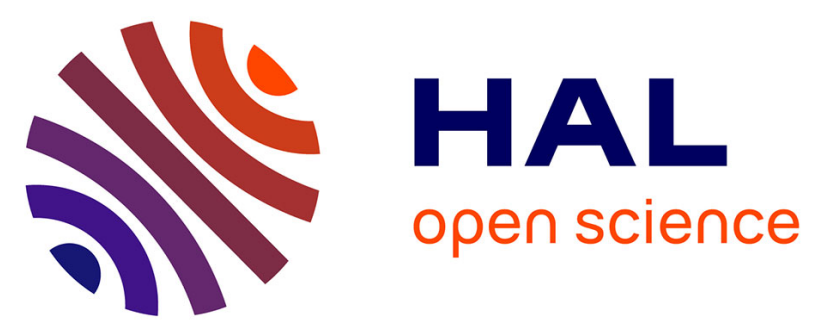

\title{
Digital Lean Cyber-Physical Production Systems: The Emergence of Digital Lean Manufacturing and the Significance of Digital Waste
}

David Romero, Paolo Gaiardelli, Daryl Powell, Thorsten Wuest, Matthias Thürer

\section{To cite this version:}

David Romero, Paolo Gaiardelli, Daryl Powell, Thorsten Wuest, Matthias Thürer. Digital Lean CyberPhysical Production Systems: The Emergence of Digital Lean Manufacturing and the Significance of Digital Waste. IFIP International Conference on Advances in Production Management Systems (APMS), Aug 2018, Seoul, South Korea. pp.11-20, 10.1007/978-3-319-99704-9_2 . hal-02164894

\section{HAL Id: hal-02164894 \\ https://hal.inria.fr/hal-02164894}

Submitted on 25 Jun 2019

HAL is a multi-disciplinary open access archive for the deposit and dissemination of scientific research documents, whether they are published or not. The documents may come from teaching and research institutions in France or abroad, or from public or private research centers.
L'archive ouverte pluridisciplinaire HAL, est destinée au dépôt et à la diffusion de documents scientifiques de niveau recherche, publiés ou non, émanant des établissements d'enseignement et de recherche français ou étrangers, des laboratoires publics ou privés. 


\title{
Digital Lean Cyber-Physical Production Systems: The Emergence of Digital Lean Manufacturing and The Significance of Digital Waste
}

\author{
David Romero ${ }^{1}$, Paolo Gaiardelli ${ }^{2}$, Daryl Powell ${ }^{3}$, Thorsten Wuest ${ }^{4}$, Matthias Thürer ${ }^{5}$

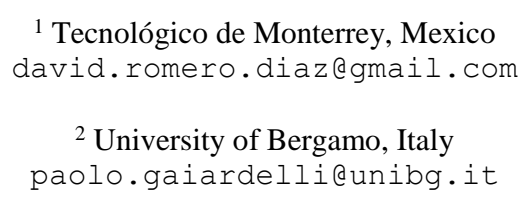 \\ ${ }^{3}$ Norwegian University of Science and Technology, Norway \\ daryl.j.powellentnu.no \\ ${ }^{4}$ West Virginia University, USA \\ thwuestemail.wvu.edu \\ ${ }^{5}$ Jinan University, China \\ matthiasthurereworkloadcontrol.com
}

\begin{abstract}
This paper explores the emergence of the next cyber/digital frontier for lean manufacturing practices. It focuses on (a) the new capabilities of information and operational technologies (ITs/OTs) for proactively detecting and eliminating potential 'physical waste' in production processes, preventing its manifestation in the real world through powerful virtual models and simulations as well as realtime performance monitoring systems based on advanced data analytics, and (b) on identifying and eliminating 'digital waste' that may come into existence in the cyber world due to the non-use (e.g. lost digital opportunities) and/or over-use (e.g. abused digital capabilities) of new digital/smart manufacturing technologies.
\end{abstract}

Keywords: Digital Manufacturing, Smart Manufacturing, Lean Manufacturing, Digital Lean Manufacturing, Digital Lean Enterprise, Cyber-Physical Production Systems, Industry 4.0, Waste, Digital Waste.

\section{Introduction}

Lean Manufacturing $(L M)$ is a systematic approach to waste minimization within a production system [1]. Lean is a toolbox that assists in the identification and elimination of waste. By eliminating waste, quality improves while production time and cost are reduced [1]. Seven forms of waste have traditionally existed within the real "physical" world of lean: defects, overproduction, waiting, transportation, inventory, motion and over-processing, plus a recent one: not-utilizing talent [2]. These $7+1$ traditional physical waste types can nowadays be better identified and eliminated through new Digital/Smart Manufacturing (D/SM) technologies [3] [4] (e.g. Big Data, Industrial Internet of Things (IIoT) and Advanced Analytics) as mechanical/physical production systems evolve into Cyber-Physical Production Systems (CPPSs) [5]. Here, established lean methods gain a new digitally-enabled edge [4] [6], hereby referred to as "Digital Lean Manufacturing (DLM)”. 
While the principles of traditional lean manufacturing will remain valid, DLM will (a) facilitate the application of these principles, and (b) enhance its scope and direction. For instance, DLM will the introduce new capabilities of information and operational technologies, such as powerful virtual models and simulations as well as real-time performance monitoring systems based on advanced data analytics that have the ability to proactively detect and eliminate 'traditional' physical waste in (physical) production processes.

However, new forms of digital waste may come into existence in the virtual/digital "cyber" world due to the new "cyber-physical" nature of production systems. Therefore, DLM will require new techniques for identifying and eliminating digital waste that may come into existence in the cyber world due to, for example, the non-use (e.g. lost digital opportunities) and/or over-use (e.g. abused digital capabilities) of new $\mathrm{D} / \mathrm{SM}$ technologies. In this context, digital waste will be defined as any non-value adding digital activity to women/men, materials, machines, methods and measurements (5M) in the Digital Lean Enterprise. This includes, for example, the creation of redundant and/or unnecessary data that is collected, managed, transmitted or stored for no tactical, operational or strategic reasons. In this case, these artefacts create unwanted and wasteful data congestion in a decision-making process [7]. On this premises, this 'position paper' explores the emergence of the next cyber/digital frontier for lean manufacturing practices, introducing a first definition of digital waste, and providing a typology for it in order to support the elimination of physical waste and at the same time the avoidance and the prevention of digital waste in the digital lean smart factory.

\section{The Emergence of Digital Lean Manufacturing}

Digital technologies have given rise to a new era of lean manufacturing, which extends the lean philosophy to the cyber world (e.g. lean automation [5] manifested as Jidoka \& Heijunka 4.0 systems [8]); for example by making 'physical-to-digital' conversions, known as 'digital transformations' or 'digitalization', of value adding activities in order to pursue new digital manufacturing levers to eventually realize higher productivity levels, higher quality, optimized resources usage and increased production throughput.

DLM builds on new data acquisition, data integration, data processing and data visualization capabilities [9] to create different descriptive, predictive and prescriptive analytics applications [10] to detect, fix, predict and prevent unstable process parameters and/or avoid quality issues inside defined tolerance ranges that may lead to any type of waste within the cyber- and physical- worlds. Hence, Digital Lean CPPSs will aim to support the operation of digital lean smart factories towards (near) zero physical and digital waste. This will be achieved, for example, by a synchronized production environment [11] (viz. digital twins [12]) between virtual models and simulations representing the virtual factory [13] that will help to design, engineer, verify and validate waste-free production operations in the cyber world before their release and ramp-up in the real factory. Digital Lean CPPSs will also help to monitor real-time performance in the physical world in order to assess whether production operations are actually being performed at their highest possible productivity level and quality standard, as planned, or if there remain opportunities for improvement (Kaizen).

Moreover, when adopting D/SM technologies to 'digitize-to-connect' and pursue vertical and horizontal factory big data integration [14] will contribute to minimize 
waste in the process of creating digital lean capabilities such as: (a) data visibility (e.g. new generation Andon systems and digital dashboards), (b) information transparency (e.g. real-time production monitoring and communication systems), and (c) (critical) events forecasting (e.g. predictability charts for continues improvement) of production operations conducted by humans, machines and computer systems on the shopfloor.

\section{The Meaning of Digital Waste}

Waste has traditionally been defined by the lean community as 'any non-value adding activity' [15] [16]. However, according to the Merriam-Webster's online dictionary definition, waste can also mean: "the loss of something valuable that occurs because too much of it is being used or because it is being used in a way that is not necessary or effective; an action or use that results in the unnecessary loss of something valuable; a situation in which something valuable is not being used or is being used in a way that is not appropriate or effective". This etymological meaning is of great importance for the definition of 'digital waste' in DLM, since it highlights the need to consider two types of digital waste: (i) passive digital waste due to missing digital opportunities to unlock the power of (existing) data, and (ii) active digital waste as a result of a data rich manufacturing environment that lacks from the proper information management approaches to derive the right amount of information to be provided at the right time to the right person, machine or information system for decision-making (knowledge).

The next sub-sections will exemplify: How a -digital lean philosophy - and D/SM technologies can contribute to reduce waste in the physical world through virtual/digital assisting means as well as How passive digital waste can be avoided and How active digital waste can be prevented. These examples may work independently or together in order to reduce or eliminate one or more types and forms of physical and digital waste.

\subsection{Eliminating Defects Waste: Digital Quality Management Lever}

Digital Quality Management (DQM) refers to the semi-automated or automated digital governance of cyber-physical production assets like smart products, smart operators and smart machines, aimed at offering real-time tracking and reporting of such intelligent assets performance towards compliance with predefined quality standards and proactively alerting in case of potential deviations from them to prevent quality problems (viz. defects) before they materialize.

Eliminating Physical Waste. New technologies, such as IIoT and cloud storage, provide real-time data (as well as easy access to historical data) from the shopfloor of the digital lean smart factory. This triggered the evolution of QM from 'sampling-based measurements' to a 'full coverage' of wo/men and machines operations in a production system. This new data lake environment on the shopfloor, combined with real-time data analytics and Advanced Process Control (APC) | Statistical Process Control (SPC) systems, has enabled the possibility for real-time error corrections in operations to minimize rework and scrap (waste) - towards zero defects. For example, (a) real-time monitoring and performance management of machine operations that allow for manufacturing processes self-adjustments to keep a quality threshold (e.g. 100\% First Pass Yield - FPY) or (b) real-time tracking of operator actions in assembly sequences based on 'context-aware wearable computing' by recognizing the operator's actions/ movements [17] and/or 'mixed reality (i.e. Augmented \& Virtual Reality) assistance 
systems' [18] by showing virtual assembly instructions directly in the operator's field of view (e.g. $100 \%$ Complete \& Accurate tasks - \%C\&A). Both approaches act as a kind of digital poka-yoke system.

Avoiding Passive Digital Waste. Advancements in electronic data processing and interchange, (enterprise) information systems and data itself have long played an important role in manufacturing operational excellence (viz. product quality, process efficiency, assets and human reliability). Hence, passive digital waste in this context may refer to the potential loss of DLM opportunities by 'quality engineers' if not upgrading their traditional quality control methods to new available techniques based on Machine Learning (ML) [10] for advanced (big) data analytics. For example, the use of a neural network to learn from historical quality control data to identify defects and predict quality deviations with a high degree of accuracy, avoiding waste due to false defect detection.

Preventing Active Digital Waste. At the same time that QM becomes digitized and data-driven, more data will be created, processed and consumed on the shopfloor. This will require more storage, computer processing power and network bandwidth as well as the (human) talent provision (e.g. setup, integration and maintenance of IT/OT systems) to support DQM. In this sense, emerging 'digital - quality engineers' will need to pursue a smart data vision rather than a big data vision, aiming always to turn big data into actionable smart data with real-business value through its application to a business process to create insights and support in-the-moment/rapid decision-making (e.g. defects real-time detection). [19] have defined four categories of waste (digital) data to be managed, in this case in a DQM business process: (a) unintentional data created as a by-product of a process with no purpose, (b) used data that serves its purpose for a period of time and then is no longer useful, (c) degraded data that has lost its quality due to whatever reason and it is no longer useful, and (d) unwanted data that was created, but never useful for any purpose.

\subsection{Eliminating Overproduction: Digital Kanban Systems Lever}

Digital Kanban Systems (DKSs) refer to real-time digital 'pull' signalling systems that use a mix of digital technologies (e.g. smart tags, smart bins/boxes, smart dashboards and smart automation) to trigger the Just-In-Time (JIT) movement of materials and electronic information (e-Kanban cards) within a digital lean smart factory in order to eliminate overproduction by being responsive to the current demand instead of forecast.

Eliminating Physical Waste. DKSs can eliminate 'overproduction' through the synchronisation between production and (raw) materials demand (of a specific item, in specific quantities, to be delivered to a specific location (e.g. smart bin or smart dashboard)) at a smart workstation, or even forecast such demand need by means of advanced data analytics, to optimize material handling and transport time as well as the time and effort needed for (e-)Kanban cards handling thanks to electronic real-time communication (viz. faster signals transfer) through e-messaging and e-alerting (sub-) systems between the workstation and its supplier(s).

Avoiding Passive Digital Waste. By not migrating to DKSs, electronic records of pull requests, recipient timestamps and delivery acknowledgements will not be able to be recorded, stored (historical data), traced and used to be analysed to reveal weak points in the JIT management of a pull production process towards zero overproduction. 
Preventing Active Digital Waste. Designing effective and efficient DKSs and their corresponding $e$-Kanban cards for the digital lean smart factory will require an emphasis on the engineering or re-engineering of input data systems (viz. smart tags and/or smart bins), processing data systems (viz. ERP + MES) and output data systems (viz. smart dashboards and smart automation (e.g. deliveries by AGVs/drones)) in order to orchestrate material and information flows JIT between workstations, warehouse(s) and intra-logistics activities and their associated information systems without synchronisation problems that may not allow to achieve a real-time material and information handling and transport system, and may cause overproduction.

\subsection{Eliminating Waiting Waste: Cyber-Physical Systems Lever}

Digital Lean CPPSs, or CPPSs-based Jidoka \& Heijunka [8] production systems, refer to autonomous and cooperative human, machine and product 'smart entities' that co-create a networked socio-technical production environment, where all software, hardware and humanware sub-systems can sense, actuate and interoperate. This is facilitated via human-machine interfaces (HMI/H2M) and machine-to-machine (M2M) communication protocols, to enable vertical and horizontal value-added data flows for the provision of a range of intelligent functions, services and features for the design and engineering, warehouse and logistics, fabrication, assembly, quality and maintenance digital lean smart factory departments.

Eliminating Physical Waste. The context-awareness capabilities of D Lean CPPSs [20] enabled by means of smart sensors, actuators and adaptive controllers can allow the smart control of the entire production processes in order to avoid waiting-times by self-adapting (re-balancing) in real-time for maximum flexibility to manage excessive demand fluctuations (Mura), and overburden of machine \& operators capacities (Muri).

Avoiding Passive Digital Waste. Thanks to new CPPSs-based Heijunka systems, all production resources (viz. wo/men, materials and machines) can be instrumented and networked in a social IIoT environment [21] [22] for supporting a 'truly holistic' production scheduling or re-scheduling in real-time and just-in-sequence logic for avoiding waste risk creation due to the lack of a systemic (re-)scheduling approach.

Preventing Active Digital Waste. When designing D Lean CPPSs environments, 'digital lean engineers' should avoid over-engineering the CPPS and adding unneeded 'complexity' to manufacturing, which may increase the potential of catastrophic, but also incremental, failure of the system. Moreover, the design principles for Industry 4.0 and CPSs [23] [24] in general advocate for decentralised structures and for small and simple-to-integrate modules (plug-and-play) in order to better manage their complexity as well as the complexity of the overall system.

\subsection{Eliminating Transportation Waste: AGVs, Drones \& 3D Printing Levers}

Automated Guided Vehicle ( $A G V$ ) Systems refer to material handling systems that use programmed AGVs - such as carts, pallets, trays or forklifts - for the transport of goods in order to support human-less intra-logistics activities at the digital lean smart factory. In a complementary way, drones, also referred as unmanned aerial vehicles (UAVs), aim to support other human-less intra-logistics activities such as visual inventory counts and searching for goods based on 'flying smart tag scanners' as well as acting as picking-and-delivery systems for goods located at the top levels of storage or shelving 
racks of high-rise warehouses. On the other hand, $3 D$ printing refers to rapid/on-demand manufacturing technology that can allow the fast production of needed items on-site.

Eliminating Physical Waste. By using $3 D$ printing for the production of low volume components on-site, reduction of transportation and even inventory waste can be realized. Furthermore, by automating pick-up, transport and delivery tasks on the shopfloor, operators can continue working at their workstations and conducting valueadding activities thanks to the support of $A G V s$ and smart conveyors. Similarly, highrise warehouses will benefit from the help of $A G V s$ and drones as highly-efficient searching, picking and delivery systems.

Avoiding Passive and Preventing Active Digital Waste. Different AGVs, drones and 3D printing solutions exist nowadays in the market at different maturity and capability levels, therefore, proper benchmarking tools should be used to grade their performance in industrial environments in order to guarantee investments that live-up to their ROI.

\subsection{Eliminating Inventory Waste: Digital Warehouse Operations Lever}

Digital Warehouse Operations (DWOs) refer to the automation of warehousing activities with the support of auto-ID technologies, smart boxes, AGVs and real-time inventory optimisation strategies to manage the ideal levels of raw materials, work-in-progress (WIP) and finished product(s) inventories.

Eliminating Physical Waste. DWOs automate 'true JIT ordering' on the basis of stock reduction by the use of diverse sensors and smart bins/boxes to manage inventory levels in collaboration with digital Kanban systems and e-billing services.

Avoiding Passive Digital Waste. Auto-ID technologies (e.g. RFID) can provide the ability to automatically compare the characteristics of all raw materials received at the warehouse based on 'purchase order data' in order to control for discrepancies that may lead to inaccurate inventory keeping beyond simple units counting.

Preventing Active Digital Waste. When relying on 'smart sensors' for automated inventory control, their appropriate selection, use and maintenance will be vital for maximizing data accuracy and providing increased confidence in inventory reports.

\subsection{Eliminating Motion Waste: New HMIs \& Wearable Computing Levers}

Human-Machine Interfaces (HMIs) refer to computer systems/technologies endowed with capabilities for enabling human-to-machine (H2M) interactions by means of data/ information interpretation from various sensory and communication channels. In a complementary way, Wearable Computing $(W C)$ refers to a wearable computer capable of sensing, storing and processing data that is incorporated into a person's clothing.

Eliminating Physical Waste. Wearable Computing can enable the tracking of operators' movements in order to build a spaghetti chart in real-time and provide motion optimization functionality as well as support for better ergonomic postures and movements to avoid injury. Correspondingly, smart workstations can be re-configured on the basis of ergonomic requirements of the individual operator (e.g. working table height and shelving unit reaching distance).

Avoiding Passive Digital Waste. New HMIs (e.g. voice control) can help operators to become hands-free in certain activities/operations, helping them to reduce time and motion when completing their tasks and therefore, improve their productivity. 
Preventing Active Digital Waste. New HMIs and wearable computing can reduce operator's physical workload, but their usage should not contribute to increase his/her cognitive workload due to complex human-machine interactions.

\subsection{Eliminating Over-Processing Waste: Digital Mfg. Standards Lever}

Digital Manufacturing Standards (DMSs) refer to the adoption of a 'common language' for ensuring the reliable and efficient integration or interoperability of very different systems, from visual management systems (interfaces) to electronic data interchanges.

Eliminating Physical Waste. Visual management systems should always comply with design standards in order to bring consistency and readability to visual monitors and visual controls in order to avoid misinterpretations and wrong actions.

Avoiding Passive and Preventing Active Digital Waste. Data interoperability standards (e.g. EDI) are a must in order to have a clear interpretation of the data shared among systems and avoid wrong actions based on such data misinterpretation.

\subsection{Eliminating Not-Utilizing Talent Waste: Digital Presence Lever}

Digital Presence (DP) refers to the use of augmented reality smart glasses and other hands-free wearable technology [17], including haptics, for 'see-what-I-see', 'hearwhat-I-hear' and even 'feel-what-I-feel' real-time communication for collaborative problem-solving between remote operators and service engineers in the field.

Eliminating Physical Waste. DP can reduce downtimes and increase fix rates of new or complex problems (e.g. troubleshooting) by enabling the possibility to tap into the specialized expertise (talent) of any service engineer on-site anytime, anywhere.

Avoiding Passive Digital Waste. Trying DP first, may enable in some occasions the possibility to get a faster diagnose and solution to a problem thanks to real-time two-way audio, video and even kinetics communication between a remote operator and a service engineer, eliminating or reducing the costly expenses of moving skilled service engineers from site-to-site to troubleshoot.

Preventing Active Digital Waste. Advancements in DP related technologies have enhanced MRO practices, nevertheless, each troubleshooting case must not disregard the possibility of the need of the physical presence of the service engineer on-site.

\section{Conclusions}

Through the exploration of D/SM technologies supporting DLM practices, this position paper provides an analysis of the different types of digital waste that may come into existence in the cyber world due to lost digital opportunities and/or abused digital capabilities of new digital/smart manufacturing technologies. The proposed approach can be adopted to identify a set of rules, policies, standards and models to govern and define which and how data is collected and managed to avoid the redundancy of unnecessary datasets towards a development path to Digital Lean CPPSs, thus minimizing digital waste in the digitalization process and improve digital lean value.

\section{References}

1. Bicheno J., Holweg, M.: The Lean Toolbox: The Essential Guide to Lean Transformation. Buckingham: PICSIE Books (2009) 
2. Liker, J.K.: The Toyota Way: 14 Management Principles from the World's Greatest Manufacturer. McGraw-Hill, New York (2004)

3. Sameer, M., Muztoba, K., Romero, D., Wuest, T.: Smart Manufacturing: Characteristics, Technologies and Enabling Factors. J. of Engineering Manufacture (2017)

4. Mora, E., Gaiardelli, P., Resta, B., Powell, D.: Exploiting Lean Benefits through Smart Manufacturing: A Comprehensive Perspective. Part I, IFIP AICT 51:127-134 (2017)

5. Kolberg, D., Zühlke, D.: Lean Automation Enabled by Industry 4.0 Technologies. IFAC Symposium on Information Control Problems in Manufacturing, 48(3):1870-1875 (2015)

6. Behrendt, A., et al.: Industry 4.0 Demystified - Lean's Next Level. McKinsey \& Co. (2017)

7. Loshin, D.: Business Intelligence and Information Exploitation. Business Intelligence, Second Edition, Chapter 1, pp. 1-13.

8. Żywicki K., Rewers P., Bożek, M.: Data Analysis in Production Levelling Methodology. Recent Advances in Information Systems and Technologies, 571:460-468, Springer (2017)

9. Kusiak, A.: Smart Manufacturing Must Embrace Big Data. Nature, 544(7648):23-25 (2017)

10. Wuest, T., et al.: Machine Learning in Manufacturing: Advances, Challenges, and Applications. Production \& Manufacturing Research, 4(1):23-45 (2016)

11. Stjepandic, J., Wekerle, T., Pfouga, A.: Advancing Smart Factories with Synced Factory Twins Approach: Representation and Scenarios for Synchronized Digital and Real Factories. Symposium on Tools and Methods of Competitive Engineering (2018)

12. Tao, F., et al.: Digital Twin-driven Product Design, Manufacturing and Service with Big Data. Int'l. J. of Advanced Manufacturing Technology (2017)

13. Pedrazzoli, P., Sacco, M., Jönsson, A., Boër, C.: Virtual Factory Framework: Key Enabler for Future Manufacturing. Digital Enterprise Technology, pp. 83-90 (2007)

14. Santos, M.Y., et al.: A Big Data Analytics Architecture for Industry 4.0. Recent Advances in Information Systems and Technologies, Vol. 570, Springer (2017)

15. Thürer, M., Tomašević, I., Stevenson, M.: On the Meaning of 'Waste': Review and Definition, Production Planning \& Control, 28(3):244-255 (2017)

16. Tamás, P., Illés, B., Dobos, P.: Waste Reduction Possibilities for Manufacturing Systems in the Industry 4.0. $20^{\text {th }}$ Innovative Manufacturing Engineering and Energy Conference (2016)

17. Perera, C., Liu, C.H., Jayawardena, S.: The Emerging Internet of Things Marketplace from an Industrial Perspective: A Survey. IEEE Transactions on Emerging Topics in Computing, 3(4):585-598 (2015)

18. Rodriguez, L.; Quint, F.; Gorecky, D.; Romero, D. and Siller R.: Developing a Mixed Reality Assistance System based on Projection Mapping Technology for Manual Operations at Assembly Workstations. Procedia Computer Science, Vol. 75, pp. 327-333.

19. Hasanand, R., Burns, R.: The Life and Death of Unwanted Bits: Towards Proactive Waste Data Management in Digital Ecosystems. $3^{\text {rd }}$ Int'l. Conf. on Innovative Computing Technology, London (2013)

20. Scholze, S., Barata, J.: Context Awareness for Flexible Manufacturing Systems Using Cyber Physical Approaches. Technological Innovation for CPSs, IFIP AICT 470:107-115 (2016)

21. Li, H., Parlikad, A.K.: Social Internet of Industrial Things for Industrial and Manufacturing Assets. 3rd IFAC Workshop on Advanced Maintenance Engineering, Service and Technology, 49(28):208-213 (2016)

22. Romero, D., Wuest, T., Stahre, J., Gorecky, D.: Social Factory Architecture: Social Networking Services and Production Scenarios through the Social Internet of Things, Services and People for the Social Operator 4.0. Part I, IFIP AICT 513:265-273 (2017)

23. Hermann, M., Pentek, T., Otto, B.: Design Principles for Industrie 4.0 Scenarios. $49^{\text {th }}$ Hawaii Int'l. Conf. on System Sciences, pp. 3928-3937, IEEE (2016)

24. Lee, J., Bagheri, B., Kao, H.A.: Recent Advances and Trends of Cyber-Physical Systems and Big Data Analytics in Industrial informatics. IEEE Int'l. Conf. on Industrial Informatics (2014) 